\title{
Study of Interaction between Professional Interest and Memorizing Based on Foreign Language Learning
}

\author{
Natalia Urushadze ${ }^{1} \&$ Natela Imedadze ${ }^{1}$ \\ ${ }^{1}$ Ilia State University, Tbilisi, Georgia \\ Correspondence: Natela Imedadze, Iliauni, Tbilisi, Georgia. Tel: 955-32-2-985-718. E-mail: \\ natela_imedadze@iliauni.edu.ge
}

Received: February 27, 2013 Accepted: March 17, 2013 Online Published: May 20, 2013

doi:10.5539/hes.v3n3p36

URL: http://dx.doi.org/10.5539/hes.v3n3p36

\begin{abstract}
This paper is an attempt to reveal conditions for professional interest activation in the process of memorization foreign lexical items by University students. The research is based on the classification of interest by D. Uznadze (viz.: formal interest and content-based interest). The investigation was conducted according to two distinct stages. In Study I, the process of memorization of foreign linguistic units went through under working memory conditions (task-based learning); In Study II, the process of memorization of linguistic items was stimulated under long-term memory conditions (text-based learning). Participants of the research were the second-year students of different specialties (Exact Sciences and Medicine) of Tbilisi State University (Level B1+). The students revealed actual intrigued interest towards the first task, but the difference between memorized special foreign terms connected or unconnected with their specialties was not reliable. Thus, professional interest was not actualized. Involvement of long-term memory and the context in the second task gave statistically confirmed difference between professionally and professionally not related texts, which points to activation of professional interest and its stimulating role in memorization of special terminology.
\end{abstract}

Keywords: interest (formal, content-based, intrigued, professional), prefixes, professional terms, professional text, task-based, text-based, mean memory span

\section{Introduction}

The present research deals with the impact of professional interest on memorizing. It is concerned with practical application of new specific terminology in English as a second language. It is axiomatic that professional interest has a great effect on the results of learning. The given research is an attempt to define the levels of interest, to measure their depth, to determine how different levels of interest differ from the qualitative point of view and how they affect the process of memorizing English special terminology aimed for special purposes.

\subsection{Literature Review}

The word "interest", used by psychologists as a term, is definitely polysemantic. B. I. Dodonov (1971) formulates his ideas on the essence of the word 'interest' in the following way: "In everyday speech it may be synonymous to such words as 'attention', 'curiosity', 'personal interest', 'enthusiasm', 'keenness for something', 'passion', 'self-interest', etc. Depending on the context, the volume of the concept of 'interest' used in everyday life may be extended, narrowed, or even shifted away from the basic circle of the scope of the involved phenomena. This word may imply a psychological process, a psychic trait of a person, or certain objective needs. Therefore, any discussion on the essence of the word 'interest' implies a risk of turning into an argument on words, where each participant is right in his own way if they do not agree beforehand which facts of psychological reality they intend to discuss and analyze."

Early conceptualizations of interest started at the beginning of the $20^{\text {th }}$ century. John Dewey (1913) was one of the first scientists who regarded interest as central to educational theory and practice. He considered interest as form of self-expression which develops and varies with age, experience, social opportunities and individual nature endowments (Kimberley, Pressick-Kilborn \& Walker, 1999). Dewey made two basic assumptions about interest. First, he believed that interest must be present in the classroom to satisfy students' intellectual and personal needs. Second, he believed that interest could be fostered by providing students with a variety of materials and educational opportunities that promoted challenge and autonomy. Dewey's writings on interest 
were followed by 50 years of silence as American Behaviorism simply chose to ignore the topic. However, with the advert of cognitive psychology in the 1960s, research and theorizing about interest steadily increased until it reached its highest level in the early and mid-1990s (Schraw, Flowerday \& Lehman, 2001). A number of scientists (Ainley, Hidi, Baird, Anderson, Harp, Mayer, Schraw, Stipek, etc.) made a valuable contribution to the development of conceptualization and classification of the kinds of interest within the frames of cognitive psychology.

Contemporary authors differentiate two kinds of interest: personal (individual) and situational. Woolfolk ., Perry \& Winne (2006) give the following description of the kinds of interest: "Personal or individual interests are more enduring aspects of the person, such as an enduring tendency to be attracted to or to enjoy subjects such as languages, history, or mathematics, or activities such as sports, music, or films. Students with individual interest in learning in general seek new information and have more positive attitude towards schooling. Situational interests are more short-lived aspects of the activity, text, or materials that catch and keep the student's attention. Both personal and situational interests are related to learning from text - greater interest leads to more positive emotional response to the material, then to greater persistence, deeper processing, better remembering of the material, and higher achievement (Ainley, Hidi \& Berndorff, 2002; Schraw \& Lehman, 2001). And interests increase when students feel competent, so even if students are not initially interested in a subject or activity, they may develop interests as they experience success(Stipek, 2002)" (Woolfolk et al., 2006, p. 384). Some scientists even have some attempts to measure interest, (e.g., Ainley and Hidi even made self-rating scales to measure interest after reading a text (Hidi, 2001). Some scientists measure interest via questionnaires, etc.)

According to a renowned Georgian psychologist D. Uznadze (1964), interest is one of the basic factors of learning. "Learning turns into completely independent psychological form of behavior due to interest existing side by side with the will and both of them are the basic components of learning creating its foundation. Learning finds the source of energy in not only cognitive understanding of the aim, but also in the inner desire, in the inner inclination, in interest without which any kind of learning becomes forced." In his opinion, the process of learning has more or less systematic nature, while interest, as a subjective inclination, is a phenomenon having accidental character. Therefore, it cannot coincide with all the moments of learning. Sometimes a student, in order to achieve his or her learning objectives, has to do something, which is not only outside the scope of his actual interest, but it is against his will. "In spite of all this", notes the author, "interest remains a significant factor of learning as it makes it easier to use the will, and therefore, promotes activation of any kind of memory."

D. Uznadze differentiates two kinds of interest: formal and content-based. Formal interest implies, for example, the method of senseless syllables (i.e., learning completely uninteresting, senseless syllables by heart if not stimulated by the interest of competition), which is not much of a value. The author underlines the importance of content-based interest: "Interest awaken by the content makes the process of systematic learning much easier if the latter deals with the content towards which the learner reveals special interest. For example, it is well known that a mathematician easily memorizes specialized material in mathematics or a botanist - material in botany. W. Stern refers to the material learnt by a conductor who remembers the orchestral score by heart. In this case, he does not learn the material by heart, but there occurs the process of inner processing of the given material, which later turns into a personal possession... Pedagogical significance of content-based interest is considered to be doubtless: it is one of the most important factors of authentic learning and genuine education" (D. Uznadze, 1964). The concept of 'interest' implies not only cognitive, but also emotional moments, which are two basic and indispensable parts of the process of learning (Harp \& Mayer, 1997; Silvia Paul J. 2006). Therefore, the best results in learning may be achieved in case of a perfect fusion of cognitive and emotional factors.

Taking into account the classifications of contemporary authors, we base our work on the kinds of interest classified by D. Uznadze (viz.: formal and content-based) and have an attempt to reveal the hypothesized sublevels of the content-based interest. We investigated the impact of interest as a factor of memorizing in the process of learning English as a second language at one of the higher educational institutions of Georgia (TSU).

We used Atkinson and Shiffrin ( Miller, 1956; Atkinson \& Shiffrin, 1968; Craik, \& Lockhart, 1972; Klatzky, 1980; Cook 1991; Baddeley, 1997; 2000;) model of memory storage for L2 students based on one of the prominent information-processing theories of memory as a general guide. According to this model, incoming information must pass through temporary storage buffers (the sensory and short-term stores) before it is transferred into long-term store. We also take into account Baddeley's model, which was applied to the second language learning by Vivian Cook (1991).

We base our research on the cognitive view and inductive method. The research has an experimental design. The 
primary hypothesis of the research is the following: Different kinds of interest have different impact on memorization of lexical items. The secondary hypothesis is the following: Professional interest causes the of memory span towards special lexical material. The experimental design allows us to draw conclusions on cause and effect and use an evenhanded procedure to assign students to two or more treatment conditions. Profession is the independent variable; the dependent variable is the number of correct answers in tests on prefixes and on special texts aroused by interest. During study I, we formulated two sub-hypotheses: (a) Special terminology without a text intrigues the learner (Study I); (b) Special terminology given in a text stimulates professional interest (Study II).

\subsection{Theoretical and Practical Implications of the Study}

This study is important from not only theoretical, but also from practical points of view, as we, English teachers at higher educational institutions, face this problem while working with the students who are at the intermediate stage of development between two courses: the Course of English as a Second Language and the Course of English for Special Purposes.

\section{Objectives}

The main goal of the present research is to reveal the conditions in which interest related to specialty promotes foreign language learning, namely, to investigate the impact of interest on memorizing of specialized lexical material. In addition to this, the research aims at revealing the levels of interest aroused in students via two tests, the main objective of which is measuring memorization of task-based (Study I) and text-based (Study II) linguistic units.

\section{Participants}

1. 100 students (aged 18-20) of the Medical Faculty of Tbilisi State University (TSU)

2. 50 students (aged 18-20) of the Faculty of Exact and Natural Sciences (TSU) with different specialties, viz.: mathematics, physics, chemistry, electronic engineering, programming, computer science, information technologies

\section{(Level B1+).}

Our research was carried out on 150 Georgian students (aged 18-20) currently studying at Tbilisi State University at two different faculties: Faculty of Exact and Natural Sciences and Faculty of Medicine. It should be underlined, that English as a second language is an obligatory subject in all higher educational institutions in Georgia. Students at Tbilisi State University are obliged to undergo the English course starting from the first level (Beginner) up to the Level B1+. The course of English for Special Purposes has not begun yet.

\section{Methods}

At the first stage of our research (Study I), we refused to use the method of meaningless items as stimuli on purpose, as it would have dealt only with awakening of formal interest. We considered necessary to use the syllables which carry their lexical meaning, i.e., Greek and Latin prefixes having international application in different fields of science, such as mathematics and medicine, i.e., connected with the future specialties of our subjects. The students had to memorize the list of eight prefixes with their corresponding lexical meanings and then match specific terms to their meanings according to the meanings of memorized prefixes. It was task-based learning without text based on induction (class-work activity).

At the second stage of our research (study II), the students skimmed and scanned two different specialized texts: a text related to specialty and a control text - unrelated to specialty, in order to stimulate all the memory stores long-term memory store included. A test on the given material (multiple-choice test with eight questions) would reveal how they memorized eight specific terms and their meanings used in the texts related to different specialties. In addition to this, it would reveal how the interest related to their specialty affected their long-term memory coefficient. It was a text-based learning (class-work, homework, class-work activities).

In order to examine the correctness of our hypotheses we carried out two studies. We used different designs of our experiments to stimulate different kinds of interest.

\section{Materials and Procedures}

\subsection{Study I}

a) The students had to read a list of eight mathematical prefixes with their meanings written beforehand on the board with the aim to memorize the list (5 minutes). 


\section{Sample:}

1. Prefixes with their meanings used in mathematics

1. quad - =four

2. tetra - $=$ four

3. hex $-\quad=$ six

Etc.

Five minutes later the teacher cleaned the board, gave out the test papers and asked the students to do the test (10 minutes), the aim of which was to match eight mathematical terms containing those prefixes with their meanings for assessment (class work activity). The score was the number of correct responses.

\section{Sample:}

\section{Test 1}

Match the terms with their definitions.

1. quadrant

2. tetrahedron

3. hexagon

Etc.

(Answer Key)

$1 \mathrm{~b} 2 \mathrm{c} 3 \mathrm{a}$, etc.

b) We followed the similar procedure with eight prefixes used in medicine. The students had to read a list of eight prefixes with their meanings written beforehand on the board with the aim to memorize the list (5 minutes).

\section{Sample:}

2. Prefixes with their meanings used in medicine

1. hyper - = over, above, beyond the norm

2. hypo - = under, beneath, less than the norm

3. post $-=$ after

Etc.

Five minutes later the teacher cleaned the board, gave out the test papers again asking the students to do the medical test (10 minutes), the aim of which was to match eight medical terms containing eight prefixes with their meanings.

Sample:

\section{Test 2}

Match the terms with their definitions.

1. hypothermia

2. postmortem

3. hyperventilation

Etc.

(Answer Key) a. a flat shape with six straight sides and six angles

b. a quarter of a circle or of its circumference

c. a solid shape with four flat sides that are triangles

$1 \mathrm{c} 2 \mathrm{a} 3 \mathrm{~b}$, etc.

After doing the test, the students checked the answers of their tests themselves according to Answer Key dictated by the teacher. During assessment mean memory span was measured according to eight correct replies of the tests.

c) Then the students filled up the questionnaire, which included the indicators of the manifested interest.

Sample:

1 . Were the tests easy or difficult? 
Easy

Average

Difficult

2. Did you enjoy doing the tests?

Yes

No

3. Which test was more interesting for you?

\section{Mathematical test}

Medical test

Both

None

Etc.

All work was carried out by the students under the direction of the teacher, who gave the instructions in English.

\subsection{Results (Study I)}

Hypothesis: (a) Special terminology without a text intrigues the learner.

The first experiment was conducted within the borders of task-based learning - it was a classroom activity inside the framework of working memory (as the test was based on maintenance rehearsal and information processing of the input).

According to the obtained data on memorizing, mean memory span, given in the second column of Table 1, was obtained from eight correct replies of the tests on specialized lexical items.

Table 1. Both group results (Study I)

\begin{tabular}{lllll}
\hline Test Type & M & SD & Std. Error & t \\
\hline $\begin{array}{l}\text { The Test Unconnected } \\
\text { With Profession }\end{array}$ & 5.780 & 1.798 & 0.147 & 1.987 \\
$\begin{array}{l}\text { The Test Connected } \\
\text { With Profession }\end{array}$ & 5.413 & 1.950 & 0.159 & \\
\hline
\end{tabular}

$\mathrm{p}>0.05$

Statistically the difference is not reliable. Mean memory span is higher in the test not related to specialty. Though special terminology without a text intrigues the students, it does not show the great difference between mean memory spans obtained from the replies in tests related to and not related to the students' professions.

The findings obtained from the questionnaire dealing with the components of interest showed that $86 \%$ of 150 students at both faculties enjoyed doing the tests (emotional component of interest) and only $14 \%$ of students did not. Only $28 \%$ of students at the Faculty of Exact and Natural Sciences chose the test on mathematical terms related to profession and $15 \%$ of students of the Medical Faculty chose the test on medical terms $(33.3 \%$ in all). In spite of the fact that $60.7 \%$ of students of both Faculties were interested in the tests on both lexical items, they could not make any choice in favor of their profession. But the total number of students who revealed interest towards each or both tests was equal to $94 \%$. We suppose that $86 \%$ indicate the emotional component of the intrigued interest, the latter stimulating cognitive activity, whereas $94 \%$ indicates actual interest-based activity. Thus the aroused intrigued interest towards the cognitive task ( $86 \%$ of students) turned into the actual interest-based activity ( $94 \%$ of students).

\subsection{Study II}

Participants of Study II were the same as in Study I.

\section{Method}

As the 'method of prefixes used in new terms', applied in Study I, did not reveal the students' preference towards 
their specialties, we considered relevant to apply a method, which would reveal professional interest by using the professional context. Namely, we used the 'method of memorizing foreign terms in the context related to their specialty.

During the second experiment, the students skimmed and scanned two different specialized texts, one of which was connected with their specialties and the other one (the text on law) - was a control text. Its main objective was to activate long-term memory store (class-work, homework). A test on the given material would reveal how the interest related to their profession affected their long-term memory span (class-work activity).

\section{Materials and Procedures}

We chose three texts in three different specialties:

1. A text on legal systems (UK): 'Legal Systems' (control-text)

\section{A text on cybernetics: 'Cybernetics'}

\section{A text on viruses: 'Viruses'}

As fifty students of the Faculty of Exact and Natural Sciences had different specialties, we chose the text on cybernetics, which, in our opinion, would be the common topic related to the future professions of the students.

At the first lesson, the students of the Faculty of Exact and Natural Sciences had to skim and scan two texts (viz.: 'The Legal Systems', which was a control text, and 'Cybernetics', the text which was related to their specialty) in class. At the end of the lesson, the texts were given for homework to be prepared for the tests, which had to be taken at the following lesson.

\section{Samples:}

Test 1 (Legal Systems)

Read the three possible replies, marked (A, B, and C), and then choose the word you believe is the closest to the given one in the text.

1. The is the body that has the function of making law; normally it is the Parliament.
A. injunction
B. procedure
C. legislature

Etc.

Answer Key

$1 \mathrm{c}$

Etc.

\section{Test 2 (Cybernetics)}

Read the three possible replies, marked (, B, and C), and then choose the word you believe is the closest to the given one in the text.

1. The word 'feedback' in the given context means

A. The information sent by the monitor to the controller.

B. The information sent by the controller to the monitor.

C. The information obtained from the controller.

Etc.

Answer Key

$1 \mathrm{~A}$

Etc.

The students of the Medical Faculty followed the similar procedure with two texts (viz.: 'The Legal Systems'control text and 'Viruses') in class. The teacher gave the texts for homework in order to prepare for the tests, which had to be taken at the following lesson. At the following lecture, the students did the test and filled up the questionnaire with seven questions. 


\section{Sample:}

1. If you were given an alternative, which topic would you choose?

a.

b.

2. What is the reason of choosing the desirable text?

a. The text is more interesting.

b. The text is related to my future profession.

\subsection{Results (Study II)}

Hypotheses: (b) Special terminology given in a text stimulates professional interest

(c) Professional interest causes the growth of memory span towards special lexical material.

The second experiment was conducted within the borders of text-based learning (classroom, homework, classroom activities) inside the framework of long-term memory.

Table 2. Both group results (Study II)

\begin{tabular}{lllll}
\hline Test Type & $\mathrm{M}$ & $\mathrm{SD}$ & Std. Error & $\mathrm{t}$ \\
\hline $\begin{array}{l}\text { The Test Unconnected } \\
\text { With Profession }\end{array}$ & 6.527 & 1.041 & 0.085 & -6.077 \\
$\begin{array}{l}\text { The Test Connected With } \\
\text { Profession }\end{array}$ & 7.187 & 0.986 & 0.080 & \\
\hline $\mathrm{p}=0.00$ & & & & \\
\end{tabular}

As shown in Table 2, the difference between memorized lexical items related to and not related to the students' profession is statistically reliable with an expressed strong preference for profession-related texts (Column 1); memory span is higher at the Faculty of Medicine. The objective indicators are based on the number of correct replies from the possible variants.

Table 3. Comparison of the results of both groups of Study I and Study II

\begin{tabular}{llllll}
\hline Text Type & Study & $\mathrm{M}$ & $\mathrm{SD}$ & Std. Error & $\mathrm{t}$ \\
\hline Unprofessional & Study I & 5.780 & 1.798 & 0.147 & -4.402 \\
Test Results & Study II & 6.527 & 1.041 & 0.085 & \\
Professional & Study I & 5.413 & 1.950 & 0.159 & -9.941 \\
Test Results & Study II & 7.187 & 0.986 & 0.80 & \\
\hline $\mathrm{p}=0.00$ & & & & &
\end{tabular}

The difference in both cases is reliable. The results of mean memory spans in Study II are higher. 


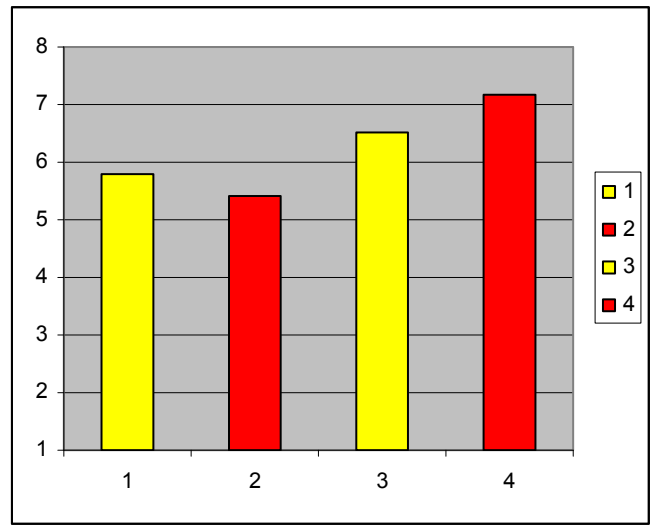

1. Test unconnected with profession: $\mathrm{M}=5.780$ (Study I)

2. Test connected with profession: $\mathrm{M}=5.413$ (study I)

3. Test unconnected with profession: $\mathrm{M}=6.527$ (Study II)

4. Test connected with profession: $\mathrm{M}=7.187$ (Study II)

Figure 1. Memory span comparison (Study I, Study II)

The findings obtained from the questionnaire showed that $87 \%$ of 150 students at both faculties made the choice in favor of professional test and only $13 \%$ of students - did not. Thus, the aroused interest was actualized in $87 \%$ of students.

\section{Discussion}

The question arises how to explain the obtained results? During the first experiment, we refused the 'method of meaningless syllables' as stimuli on purpose, as it would have dealt only with awakening of formal interest. Instead, we applied the 'method of prefixes' used in special terms without a text (Zimmerman, 1989). We supposed that prefixes, which play an important role in such fields of science as medicine, mathematics etc., together with the terms containing those prefixes with their meanings, would arouse professional interest in corresponding fields of science. We tried to obtain additional data dealing with the levels of interest with the help of a questionnaire, where we asked the students if they enjoyed doing the test or not. It would show whether the test intrigued the students or not. The answer to the second question (which test, viz.: mathematical, medical, both or none was more interesting for them) would be an indicator of the type of interest the test aroused. We expected that such a test would switch on and activate the students' working memory within the short-term memory store, which is responsible for maintenance rehearsal and information processing and is an intermediate stage towards decision making in favor of their profession. In addition to this, it would strengthen the students' will from the viewpoint of their broader application. In the questionnaire, the students proved the existence of intrigued interest, but not the professional one. The obtained results supported our secondary hypothesis that special terminology without a text intrigues the learner.

The data, based on responses of students on the mean memory span given in Table 1, did not reveal the preferences towards professional test. The reason might be the absence of an objective factor i.e., the professional context (a text), which did not exist there. Thus, it seems that the aroused intrigued interest is an intermediate level between formal (actual) and content-based professional interest. Here there was no differentiation according to correct replies in linguistic units related to and not related to profession. In spite of the fact that the results did not show the students' preferences towards their profession, the test intrigued the students towards cognitive activity of memorization while matching the terms with prefixes with their definitions (94\% in both groups). We reached our objective, as in Study I we wished to prepare the background for revealing professional interest for Study II. The obtained data proved that special terminology without a text aroused intrigued interest, which we supposed to be the primary level of professional interest.

The test together with a questionnaire tapped not only cognition of reasoning, problem solving and assessing of the obtained results, but it also left some empty space for new questions, which, for its part, would promote the students for further learning.

To sum up, in the first experiment, the students who were given a task to memorize certain lexical items 
(maintenance rehearsal and information processing within the short-term memory store) did not reveal the preferences towards lexical items related to their future professions. We may assume that verbal items without the context did not prove to be enough to stimulate professional interest, though it confirmed the existence of intrigued interest.

The question arises: How did the memory system work during the test from the viewpoint of the Information Processing Model of Memory in the first experiment? According to Baddeley's model, information flew into the sensory memory block, underwent pattern recognition, passed through the temporary storage buffer, and activated the main components of working memory, viz.: Phonological Loop (short-term buffer) responsible for recycling items for immediate recall. Both types of rehearsal were involved: Maintenance rehearsal, which was responsible for repeating the information in the mind as well as Elaborative rehearsal (Woolfolk et al., 2006, Baddeley, 1997). The retrieval was immediate. In this case, we deal with the working memory (class-work activity). The stimulation connected with profession did not have sufficient effect on memorization of specific lexical items in favor of profession.

In the second experiment, the information passed through two temporary storage buffers (the sensory and short-term memory stores) before it could be transferred into long-term storage (Class-work activity).The long-term memory, which is relatively slow and practically unlimited, was actively involved in the process (Home-work activity). There was a close relationship between conscious attention and encoding in long-term memory. Retrieval of the material occurred during the test (Class work activity: assessment). The input was recycled through the phonological loop as its activation level was refreshed and there took place two types of rehearsal again: maintenance rehearsal and elaborative rehearsal responsible for connecting the newly processed information with the information they already knew (John N. Williams, 1999). The second component was Visuospatial Sketchpad responsible for visual, imagery tasks within the general system of Central Executive, the latter being responsible for initiative control and decision-making processes, reasoning and language comprehension. It was also responsible for draining executive resources when the task was difficult.

To sum up, in the second experiment, when linguistic items were given in the context, the long-term memory store was activated (Class-work, homework, class-work activities). Memorization of professional terms occurred in a privileged position (Williams, 1999, p. 2; Robinson (1995). The question arises: Did professional interest participate in the described process? The results obtained in Study II confirm priority of fulfillment of the test connected with profession. The obtained results supported our hypothesis that professional interest causes the growth of memory span towards foreign special lexical material.

The central role of working memory in foreign language learning was investigated by Vivian Cook in her book 'Second Language Learning and Language Teaching' (1991). The author argued that cognitive processes including memorization work less efficiently in the second language and that the span of unconnected digits should have certain quantitative restrictions in L2, namely the material to be memorized in working memory should not be more than 15 syllables long. But our research was an attempt to reveal the conditions in which the quantity of the material to be memorized may increase via involvement of professional interest, which, for its part, makes the cognitive process more profound and effective.

It should be underlined, that the levels of interest, which differ in depth, may become interwoven, they may even interact with each other, but the borders between the levels of interest may be so fragile that it might be difficult to draw a line between them. A lot depends on students' scope of individual interests, on the material they deal with (content-based interest) and on the teacher's observation abilities, experience, skills and competence.

It seems that the impact of the kinds of interest and their levels on memorizing have certain dynamics during students' specialization in the narrower fields of science, which may be the subject of further research. We have compiled an English textbook for special purposes. It deals with the topics concerning biology, which may be helpful from this point of view.

\section{Conclusions}

We base our research on the classification of interest by D. Uznadze (viz.: formal and content-based). Based on experimental findings, the content-based interest has intrigued and professional sublevels. The intrigued interest is concerned with the situation when someone is very interested in something wanting to know more about it. The term 'intrigued' posits not only 'situational' interest, caused by external aspects of activities, such as complexity, novelty, uncertainty, etc. (Hidi, 1988; Hidi, 1990; Hidi \& Anderson, 1992), but it gives advantage over the term 'situational' in the process of learning, as it implies the moment of enquiring. Content-based Professional interest is concerned with enduring interest in profession (Individual interest). All kinds of interest differ in depth, are interwoven and interact with each other, have different stimulating power and different 
impact on memorization of the target material in a foreign language.

According to the obtained data, we have come to the following conclusions: the task of memorizing special lexical items without a text arouses intrigued interest (Study I); the task of memorizing special terminology given in a text arouses professional interest (Study II); professional interest causes the growth of memory span towards special lexical material (Study II). All the processes described above take place when the level of English language (L2) proficiency corresponds to B1 or B1+. Hence, we confirmed our primary hypothesis that different kinds of interest have different impact on memorization of lexical items.

\section{References}

Ainley, M., Hidi, S., \& Berndorff, D. (2002). Interest, learning and the psychological processes that mediate their relationship. Journal of Educational Psychology, 94(3). http://dx.doi.org/10.1037/0022-0663.94.3.545

Atkinson, R. S., \& Shiffrin, R. M. (1968). Human Memory: A proposed System and its control processes. In K. V. Spence, \& J. T. Spence (Eds.), The Psychology of learning and motivation (Vol. 2). New York: Academic Press.

Baddeley, A. (1997). Human Memory, Theory and Practice. London: Psychology Press.

Baddeley, A. (2000). Short-term and Working Memory. In E. Tulving, \& F. I. M. Craik (Eds.), The Oxford Handbook of Memory. New York: Oxford University Press.

Cook, V. (1991). Second Language Learning and Language Teaching. London: Edward Arnold, A division of Hodder \& Stoughton.

Craik, F. I. M., \& Lockhart, R. S. (1972). Levels of Processing: A Framework for Memory Research. Journal of Verbal Learning and Verbal Behavior, 11. http://dx.doi.org/10.1016/S0022-5371(72)80001-X

Dewey, J. (1979). Interest and Effort in Education. In J. A. Boydston (Ed.), The Middle Works, 1899-1924: Vol. 7: 1912-1914. Carbondale, IL: Southern Illinois University Press (Original work Published in 1913).

Dodonov, B. I. (1971). On the essence of interests and the approach to their research. Soviet Pedagogy, 1971(9), 72-81.

Harp, S. F., \& Mayer, R. E. (1997). The role of interest in learning from scientific text and illustrations: On the distinction between emotional interest and cognitive interest. Journal of Educational Psychology, 89(1). http://dx.doi.org/10.1037/0022-0663.89.1.92

Hidi, S. (1990). Interest and its contribution as a mental resource for learning. Rev. Educ. Res., 60.

Hidi, S. (2001). Interest, Reading and learning: Theoretical and Practical Considerations. Educational Psychology Review, 13(3), 11-12. http://dx.doi.org/10.1023/A:1016667621114

Hidi, S., \& Anderson, V. (1992). Situational interest and its impact on reading and expository writing. In K. A. Renninger, S. Hidi, \& A. Krapp (Eds.), The Role of Interest in Learning and Development. Hillsdale, NJ: Erlbaum.

Hidi, S., \& Baird, W. (1988). Strategies for increasing text-based interest and students' recall of expository texts. Reading Res.Q.23. http://dx.doi.org/10.2307/747644

Klatzky, R. (1980). Human Memory: Structures and processes (pp. 8-124). Second Edition. San Francisco: W. H. Freedom and Company.

Miller, G. A. (1956). The magic number seven, plus or minus two: Some limits on our capacity for processing information. Psychological Review, 63. http://dx.doi.org/10.1037/h0043158

Pressick-Kilborn, K. J., \& Walker, R. A. (1999). Exploring conceptualizations of students' interest in learning: The need for a sociocultural theory. University of Sydney. Paper presented at the Annual Conference of the Australian Association for Research in Education/New Zealand Association for Research in Education. Melbourne, Australia 29 Novemeber - 2 December, 1999.

Robinson, P. (1995). Attention, memory, and the 'Noticing' hypothesis. Language Learning, 45. http://dx.doi.org/10.1111/j.1467-1770.1995.tb00441.x

Schraw, G., \& Lehman, S. (2001). Situational Interest: A Review of the Literature and Directions for Further research. Educational Psychology review, 13(1). http://dx.doi.org/10.1023/A:1009004801455

Schraw, G., Flowerday, T., \& Lehman S. (2001). Increasing Situational Interest in the Classroom. Educational Psychological Review, 13(3), 212-214. http://dx.doi.org/10.1023/A:1016619705184 
Silvia, P. J. (2006). Exploring Psychology of Interest. New York: Oxford University Press, Inc. http://dx.doi.org/10.1093/acprof:oso/9780195158557.001.0001

Stipek, D. (2002). Motivation to learn: from theory to practice. Needham Heights, MA: Allyn \& Bacon.

Uznadze, D. (1964). Works III - IV. The Publishing House of Georgian Academy of Science (Original in Georgian).

Williams, J. N. (1999). Memory, Attention and Inductive Learning. Studies in Second Language Acquisition, 21(1), 1-5.

Woolfolk, A. E., Perry, N., \& Winne, P. (2006). Educational Psychology. Toronto, CA: Pearson.

Zimmerman, F. (1989). English For Science (pp. 42, 74, 132). A Division of Simon \& Schuster, Englewood Cliffs, New Jersey, Printed in the United States of America, by Prentice-Hall, Inc. 